\title{
Quality evaluation of Alpinia oxyphylla after Aspergillus flavus infection for storage conditions optimization
}

\author{
Xiangsheng Zhao ${ }^{1}$, Jianhe Wei ${ }^{1,2}$, Yakui Zhou ${ }^{1}$, Weijun Kong ${ }^{2^{*}}$ and Meihua Yang ${ }^{1,2^{*}}$
}

\begin{abstract}
In the storage of Alpinia oxyphylla, growth of mildew (especially toxic fungi, such as Aspergillus flavus) is a potential safety risk. Few reports have investigated how A. oxyphylla storage conditions impact mold growth or how mold growth impacts the bioactive components of A. oxyphylla. In this study, sterilized A. oxyphylla samples were contaminated by artificial inoculation of $A$. flavus spores. The main chemical components and aflatoxin levels in the infected A. oxyphylla samples were characterized. Central composite design-response surface methodology was used to study the effects of different temperature and humidity of storage conditions on the fungal growth in A. oxyphylla and accumulation of aflatoxins. The results showed that aflatoxins levels can be minimized by storing samples at temperatures below $25^{\circ} \mathrm{C}$ and with humidity less than $85 \%$. Additionally, we found that the yield and composition of volatile oil in A. oxyphylla exhibited small changes due to mold growth. However, polysaccharide content reduced remarkably. Temperatures below $25^{\circ} \mathrm{C}$ and humidity below $85 \%$ were the best storage conditions to preventing A. oxyphylla from becoming moldy. Our results provide the theoretical basis for future studies the effects of storage conditions and mold growth on the quality and safety of traditional Chinese medicines (TCMs).
\end{abstract}

Keywords: Alpinia oxyphylla, Aspergillus flavus, Aflatoxins, Storage conditions, Quality evaluation

\section{Introduction}

Fungal contamination of medicinal plants can occur at any stage, from cultivation to sale in locations throughout the world. In tropical and subtropical areas in particular (Zhang et al. 2012), high temperatures and increased humidity are conducive for fungal growth and mycotoxin production. Mildew can degrade or destroy the active ingredients and produce toxic compounds, which reduces the efficacy of medicinal plants, and influences the quality and safety of their final products (Wang et al. 2015). Aspergillus and Fusarium fungi, including Aspergillus flavus, have been reported as the most common species of fungi in medicinal plants (Battilani et al. 2016). These species are of special concern because they can produce mycotoxins [e.g. aflatoxins

\footnotetext{
*Correspondence: kongwj302@126.com; yangmeihua15@hotmail.com ${ }^{2}$ Institute of Medicinal Plant Development, Chinese Academy of Medical Sciences \& Peking Union Medical College, Beijing 100193, China Full list of author information is available at the end of the article
}

(AFs), ochratoxin A] that pose potentially serious threats to human and animal health, due to their acute and chronic toxicity (Qin and Guo 2011). Hence, in recent years, fungal contamination, together with mycotoxin production, in medicinal plants has garnered growing attention.

Alpinia oxyphylla (Yizhi in Chinese, A. oxyphylla), the dried ripe fruits of Alpinia oxyphylla Miq, is a folk medicine with broad anti-inflammatory, anti-allergy, antiulcer and neuroprotective effects that can be used to treat intestinal disorders, diuresis, ulceration, dementia and other diseases (Li et al. 2013). In addition, A. oxyphylla is also consumed as a food in China. Phytochemical studies have indicated that it contains volatile oils, polysaccharides, flavonoids and diarylheptanoids ( $\mathrm{Li}$ et al. 2013; Feng et al. 2015; Zhao et al. 2013). Because it is widely distributed in tropical and subtropical regions, $A$. oxyphylla can become moldy during its growth, harvesting, processing and storage. Environmental conditions, such as high temperature and humidity, are crucial for fungal 
contamination and mycotoxin production (Amelin et al. 2013). It has been reported that AFs contaminate up to $100 \%(n=3)$ of $A$. oxyphylla samples, with maximum contamination levels of $0.81 \mu \mathrm{g} / \mathrm{kg}$ for $\mathrm{AFB}_{1}$ and $10.3 \mu \mathrm{g} /$ $\mathrm{kg}$ for all $\mathrm{AFs}$ (the sum of $\mathrm{AFB}_{1}, \mathrm{AFB}_{2}, \mathrm{AFG}_{1}$ and $\mathrm{AFG}_{2}$ ) (Zha et al. 2014). Another report found that A. oxyphylla contained $\mathrm{AFB}_{1}$ at levels (up to $20 \mu \mathrm{g} / \mathrm{kg}$ ) higher than the maximum residue limits established by the Chinese Pharmacopoeia (Zhang et al. 2008; Chinese Pharmacopoeia Commission 2015). These results suggested that A. oxyphylla might be infected by some species of Aspergillus during storage. Additionally, the authors observed that $A$. oxyphylla was commonly found to be moldy under improper storage conditions. However, as far as we know, research into the effects of storage conditions on A. oxyphylla quality and mold contamination has not been reported.

Hence, the aims of the present study were to (1) determine the ideal storage conditions (including temperature and humidity) for $A$. oxyphylla to prevent $A$. flavus infection and (2) to evaluate the impact of mold growth on $A$. oxyphylla quality. Using a trans-culturing approach, sterilized $A$. oxyphylla was artificially inoculated with $A$. flavus spores for cultivation. Central composite designresponse surface methodology was used to study the effects of different storage temperature and humidity conditions on fungal growth in A. oxyphylla and subsequent production of aflatoxins. The volatile compound and polysaccharide composition was then determined by gas chromatography-mass spectrometry (GC-MS) and spectrophotometry, respectively. Aflatoxins (including $\mathrm{AFB}_{1}, \mathrm{AFB}_{2}, \mathrm{AFG}_{1}$ and $\mathrm{AFG}_{2}$ ) were detected by ultra-performance liquid chromatography coupled with tandem mass spectrometry (UPLC-MS/MS). This is the first study to optimize the storage conditions for A. oxyphylla, which will provide the theoretical basis to establish the most effective system to protect $A$. oxyphylla from mold infection during its storage.

\section{Materials and methods \\ Chemicals, reagents and materials}

Methanol, acetonitrile and ethyl acetate (Merck, Darmstadt, Germany) were of HPLC grade. All other chemical solvents of analytical grade were obtained from Beijing Chemical Reagents Co. (Beijing, China). Deionized water was prepared using a Milli-Q water purification system (Millipore Corporation, USA). Reference standards for $\mathrm{AFB}_{1}, \mathrm{AFB}_{2}, \mathrm{AFG}_{1}, \mathrm{AFG}_{2}$ were bought from Solarbio (Beijing, China). Nootkatone was obtained from SigmaAldrich Co. Ltc. (Shanghai, China). The purities of all the above reference compounds were above $98 \%$. Aspergillus flavus strains were supplied by China General Microbiological Culture Collection Center (CGMCC 3.4410,
Beijing, China). Aflatoxin-free A. oxyphylla samples were collected from Wuzhishan city, Hainan province, China.

\section{Instrumentation}

UPLC coupled with a QTRAP 6500 triple quadruple mass spectrometer (AB Sciex, Toronto, ON, Canada) with electrospray ionization (ESI) was used to analyze $A$. oxyphylla samples. Chromatographic separation of four aflatoxins was performed on an Acquity $\mathrm{BEH} \mathrm{C}_{18}$ column $(100 \mathrm{~mm} \times 2.1 \mathrm{~mm}$ i.d. $1.7 \mu \mathrm{m}$, Waters Corp., Milford, MA, USA). The mobile phase consisted of $0.2 \mathrm{mM}$ ammonium acetate water $(\mathrm{A})$ and $\mathrm{MeOH}$ containing $0.1 \%$ formic acid (B) at a flow rate of $0.3 \mathrm{~mL} / \mathrm{min}$. A gradient program was used as follows: 0 min: $25 \%$ A; 2 min: $45 \%$ A; 10 min: $90 \%$ A; 12 min: $90 \%$ A; 12.1 min: $25 \%$ A. The injection volume was $2 \mu \mathrm{L}$ and the column temperature was set to $35^{\circ} \mathrm{C}$. ESI-MS/MS analyses were performed in positive ionization mode. The ionization source parameters were as follows: $550^{\circ} \mathrm{C}$, curtain gas (nitrogen), $35 \mathrm{psi}$; ion spray voltage $5000 \mathrm{~V}$ in positive mode; Gas $160 \mathrm{psi}$ and Gas 255 psi. Data were acquired using the multiple reaction monitoring (MRM) scan mode. Two precursorto-product ion transitions were simultaneously monitored at $m / z$ 313.0-285.0, 313.0-269.0 for $\mathrm{AFB}_{1} ; \mathrm{m} / z$ $315.0-259.0,315.0-287.0$ for $\mathrm{AFB}_{2} ; m / z$ 329.0-243.0, $329.0-215.0$ for $\mathrm{AFG}_{1} ; \mathrm{m} / z$ 331.0-245.0, 331.0-285.0 for $\mathrm{AFG}_{2}$. Instrumental data were collected using the Analyst ${ }^{\circledR}$ Software version 1.6.2 with Schedule MRM TM Algorithm (AB Sciex, Toronto, ON, Canada).

Gas chromatography-mass spectrometry analyses were carried out using a gas chromatography-ISQ 3000 mass spectrometer (Thermo Scientific, San Jose, CA, USA) with a TG-5 MS capillary column $(30 \mathrm{~m} \times 0.25 \mathrm{~mm}$ i.d. $0.25 \mathrm{~mm}$ film thickness, Thermo Scientific, USA). Injection volume was $1.0 \mu \mathrm{L}$ in split ratio of 10:1. Helium was used as carrier gas at $1.5 \mathrm{~mL} / \mathrm{min}$. Oven temperature was programmed as follows: initial temperature $50{ }^{\circ} \mathrm{C}$ for $3 \mathrm{~min}$, raised to $75{ }^{\circ} \mathrm{C}\left(15{ }^{\circ} \mathrm{C} / \mathrm{min}\right)$ for $0.5 \mathrm{~min}$, raised to $110{ }^{\circ} \mathrm{C}\left(20^{\circ} \mathrm{C} / \mathrm{min}\right)$ for $1 \mathrm{~min}$, raised to $130{ }^{\circ} \mathrm{C}\left(2{ }^{\circ} \mathrm{C} /\right.$ min), raised to $140{ }^{\circ} \mathrm{C}\left(1{ }^{\circ} \mathrm{C} / \mathrm{min}\right)$ and raised to $250{ }^{\circ} \mathrm{C}$ $\left(5{ }^{\circ} \mathrm{C} / \mathrm{min}\right)$ for $10 \mathrm{~min}$. The temperature injector and $\mathrm{MS}$ transfer line were kept at $220^{\circ} \mathrm{C}$ and $250^{\circ} \mathrm{C}$, respectively. Ionization was carried out in electron-impact ionization (EI) mode at $70 \mathrm{eV}$. The ion source temperature was set at $280{ }^{\circ} \mathrm{C}$. The mass spectra were recorded within $40-500 \mathrm{amu}$ in full scan mode.

\section{Response surface methodology for optimization of storage conditions}

The reported optimum temperature and relative humidity for A. flavus growth are $20-40{ }^{\circ} \mathrm{C}$ and $80-95 \%$ (Hu et al. 2015), respectively. Similarly, the optimum temperature for the production of aflatoxin is $20-30{ }^{\circ} \mathrm{C}$. 
Therefore, in this study, response surface methodology (RSM) with five levels $( \pm 1, \pm \alpha$ and one central point) and two-factor (temperature and humidity) central composite design $(\mathrm{CCD})$ was used to optimize the storage conditions to prevent the infection of $A$. oxyphylla by $A$. flavus. The independent variables and their values for this study are shown in Table 1 . The design consisted of 13 total experimental runs, which were analyzed using the Design expert 8.0.7.1 (Stat-Ease Inc. USA) statistical software package.

Two hundred grams of $A$. oxyphylla samples were sterilized under a UV lamp for $2 \mathrm{~h}$. Then the sterilized samples were divided into a control group (100 g) and an infection group (100 g). One milliliter of A. flavus spore suspension $\left(10^{6}\right.$ colony forming unit $\left./ \mathrm{mL}\right)$ was added to the infection group samples, while $1 \mathrm{~mL}$ sterile water was added to the control group samples. The samples from the two groups were cultured under the same conditions for 10 days as a single experimental run. All the samples for 13 experimental runs were sterilized and dried for analysis.

\section{Determination of aflatoxin concentration by UPLC-MS/MS}

At each time point, the cultured A. oxyphylla samples were prepared for aflatoxin $\left(\mathrm{AFB}_{1}, \mathrm{AFB}_{2}, \mathrm{AFG}_{1}\right.$ and $\mathrm{AFG}_{2}$ ) analysis by UPLC-MS/MS according to the reported procedure and methods (Zhao et al. 2017). One gram of ground powder was placed into a $15-\mathrm{mL}$ polycarbonate centrifuge tube, and was extracted with $4 \mathrm{~mL}$ of ACN-water-acetic acid (79:20:1, $v / v / v)$. The tube was tightly capped and vortexed for $1.0 \mathrm{~min}$, and then was placed into an ultrasonic bath at $40{ }^{\circ} \mathrm{C}$ for $20 \mathrm{~min}$. The extracts were subsequently centrifuged for $15 \mathrm{~min}$ at $12,000 \mathrm{rpm}$. The supernatant was filtered through a $0.22-$ $\mu \mathrm{m}$ filter for UPLC-MS/MS analysis.

\section{Thin-layer chromatography of volatile oil}

Alpinia oxyphylla volatile oils were prepared by hydrodistillation. Detailed methodology was as follows: $50 \mathrm{~g}$ of the ground powder was soaked in distilled water (tenfold volume) for $1.5 \mathrm{~h}$, and extracted through steam distillation for $6 \mathrm{~h}$. Then, the essential oils were dried over anhydrous sodium sulfate and sealed in an amber volumetric flask. Twenty-five microliters of the volatile oil was dissolved in $1.0 \mathrm{~mL}$ ethyl acetate for thin-layer chromatography (TLC) analysis.

Five microliters of the volatile oil solvents were separately applied on $20 \times 20 \mathrm{~cm}$ chromatographic plates pre-coated with silica gel (Merck, Germany) as the stationary phase. The chromatograms were developed in a glass chamber containing cyclohexane-ethyl acetate (9:1, $v / v)$ as the mobile phase. The plates were dried for $5 \mathrm{~min}$ and inspected under a UV lamp at $365 \mathrm{~nm}$. TLC detection was performed in duplicate for all samples.

\section{GC-MS analysis}

One gram of ground powder was extracted with $3 \mathrm{~mL}$ of ethyl acetate by sonication at room temperature for $30 \mathrm{~min}$. The solution was adjusted to the original weight with ethyl acetate. The extracts were subsequently centrifuged at $5000 \mathrm{rmp}$ for $10 \mathrm{~min}$. Before being injected into the GC-MS, all solutions were filtered through $0.22-\mu \mathrm{m}$ membrane filters.

Table 1 Contents of AFs in Alpinia oxyphylla inoculated with A. flavus stored under different conditions

\begin{tabular}{|c|c|c|c|c|c|c|c|}
\hline \multirow[t]{2}{*}{ No. } & \multirow[t]{2}{*}{ Temperature $\left({ }^{\circ} \mathrm{C}\right)$} & \multirow[t]{2}{*}{ Humidity (\%) } & \multicolumn{5}{|c|}{ Content $(\mu \mathrm{g} / \mathrm{kg})$} \\
\hline & & & $\mathrm{AFB}_{1}$ & $\mathrm{AFB}_{2}$ & $\mathrm{AFG}_{1}$ & $\mathrm{AFG}_{2}$ & Total \\
\hline A & 22.93 & 82.20 & $<\mathrm{LOQ}$ & ND & ND & ND & $<\mathrm{LOQ}$ \\
\hline B & 37.07 & 82.20 & 0.59 & ND & ND & ND & 0.59 \\
\hline$C$ & 22.93 & 92.80 & 1.77 & ND & ND & ND & 1.77 \\
\hline $\mathrm{D}$ & 37.07 & 92.80 & 5.33 & ND & ND & ND & 5.33 \\
\hline$E$ & 20.00 & 87.50 & $<\mathrm{LOQ}$ & ND & ND & ND & $<\mathrm{LOQ}$ \\
\hline $\mathrm{F}$ & 40.00 & 87.50 & 0.44 & ND & ND & ND & 0.44 \\
\hline G & 30.00 & 80.00 & $<\mathrm{LOQ}$ & ND & ND & ND & $<\mathrm{LOQ}$ \\
\hline $\mathrm{H}$ & 30.00 & 95.00 & 8.90 & 0.59 & ND & ND & 9.49 \\
\hline । & 30.00 & 87.50 & 2.38 & ND & ND & ND & 2.38 \\
\hline J & 30.00 & 87.50 & 2.48 & ND & ND & ND & 2.48 \\
\hline K & 30.00 & 87.50 & 2.44 & ND & ND & ND & 2.44 \\
\hline$L$ & 30.00 & 87.50 & 2.53 & ND & ND & ND & 2.53 \\
\hline M & 30.00 & 87.50 & 2.47 & ND & ND & ND & 2.47 \\
\hline
\end{tabular}

Storage condition numbering in this paper is the same as shown in this table ND not detected 


\section{Determination of polysaccharide content}

Polysaccharides were extracted from A. oxyphylla and detected according to the described protocol (Zhao et al. 2013). Half a gram of $A$. oxyphylla powder was weighed and placed into the extractor, then extracted by reflux with $25 \mathrm{~mL}$ petroleum ether $\left(60-90{ }^{\circ} \mathrm{C}\right)$ and $25 \mathrm{~mL}$ $80 \%$ ethanol for $2 \mathrm{~h}$, twice. Afterwards, the residue was extracted by reflux with $25 \mathrm{~mL}$ deionized water at $95^{\circ} \mathrm{C}$ for $2 \mathrm{~h}$, twice. Then, deionized water was added to the combined filtrate to achieve a final volume of $100 \mathrm{~mL}$. One milliliter of the extract was transferred into a $10 \mathrm{~mL}$ test tube and $4 \mathrm{~mL}$ of anhydrous alcohol was added for precipitation overnight at $4{ }^{\circ} \mathrm{C}$. The solution was centrifuged ( $6000 \mathrm{rpm}, 10 \mathrm{~min}$ ) to remove the supernatant. The precipitate was then dissolved in $500 \mathrm{~mL}$ deionized water for further analysis. One milliliter of sample solution was put into a test tube, then $1 \mathrm{~mL}$ phenol solution (5\%) and $5 \mathrm{~mL}$ sulfuric acid were added and test tubes were shaken for $30 \mathrm{~s}$. The test tube was heated by boiling in a water bath for $10 \mathrm{~min}$, then was cooled to room temperature in an ice bath. The absorbance was measured at $484 \mathrm{~nm}$. The polysaccharide content was calculated based on a standard curve of glucose.

\section{Results}

\section{Aflatoxin detection in A. oxyphylla}

All $A$. oxyphylla samples were cultured for 10 days under different storage conditions that were designed using CCD. Our findings show that mold growth in A. oxyphylla were different. As was shown in Additional file 1: Figure $\mathrm{S} 1, A$. oxyphylla samples were enveloped by hypha after storage in $30^{\circ} \mathrm{C}$ and $95 \%$ humidity conditions. However, no hypha were observed on $A$. oxyphylla surfaces after storage in $20{ }^{\circ} \mathrm{C}$ and $87.5 \%$ humidity conditions. $\mathrm{AFB}_{1}, \mathrm{AFB}_{2}, \mathrm{AFG}_{1}$ and $\mathrm{AFG}_{2}$ levels were determined by optimized UPLC-MS/MS and the results are shown in Table 1 and Additional file 1: Figure S2. The linearity, and limits of detection (LOD) and quantification (LOQ) of the four investigated aflatoxins were determined and are shown in Additional file 1: Table $\mathrm{S} 1 . \mathrm{AFB}_{1}$ was detected in all the samples, however aflatoxin content was below the LOQ $(0.10 \mu \mathrm{g} / \mathrm{kg})$ for sample No.1 (Temperature: $22.93{ }^{\circ} \mathrm{C}$, Humidity: $82.2 \%$ ), No.5 (Temperature: $20.0{ }^{\circ} \mathrm{C}$, Humidity: 87.5\%) and No. 7 (Temperature $30.0{ }^{\circ} \mathrm{C}$, Humidity $80.0 \%)$. $\mathrm{AFB}_{2}$ was only detected in sample No. 8 (Temperature: $30.0{ }^{\circ} \mathrm{C}$, Humidity: $95.0 \%$ ) at a concentration of $0.59 \mu \mathrm{g} / \mathrm{kg}$. The $\mathrm{AFB}_{1}$ content in sample No. 8 exceeded the limit set by Chinese Pharmacopoeia, and the total aflatoxin content $\left(B_{1}+B_{2}+G_{1}+G_{2}\right)$ was close to the maximum residue limits (MRL, $10 \mu \mathrm{g} / \mathrm{kg}$ ). Additionally, the $\mathrm{AFB}_{1}$ concentration $(5.33 \mu \mathrm{g} / \mathrm{kg})$ in sample No.4 (Temperature: $37.07{ }^{\circ} \mathrm{C}$, Humidity: $92.8 \%$ ) also exceeded the MRL. For all the other samples, the content of $\mathrm{AFB}_{1}$ and total aflatoxins were within the acceptable range. $\mathrm{AFG}_{1}$ and $\mathrm{AFG}_{2}$ were not detected in any samples.

\section{Volatile oil yield}

Volatile oils are the main constituents of A. oxyphylla, and have been chosen as a quality control marker by the Chinese Pharmacopoeia (Chinese Pharmacopoeia Commission. 2015). Our results show that the volatile oil yields of $A$. oxyphylla ranged from 0.82 to $1.33 \mathrm{~mL} / 100 \mathrm{~g}$ under normal storage conditions and were between 0.94 and $1.14 \mathrm{~mL} / 100 \mathrm{~g}$ in experimental storage conditions (Miao et al. 2015). Mold growth caused small changes in volatile oil yield (Fig. 1) from A. oxyphylla, showing that mold infection could not influence the volatile oil content of this TCM.

\section{TLC analysis of volatile oil}

Thin-layer chromatography is a very popular technique for the assessment of TCMs in Chinese Pharmacopoeia, due to the advantages of lower cost, less rigorous sample preparation, higher throughput, and easier visualization (Sowa and Subbaiah 2004). Although A. flavus infection caused small changes in the volatile oil yield of $A$. oxyphylla, the effect on its composition was unknown. Thus, we developed a convenient and cheap TLC method that targets only the essential oils. Photo documentation of TLC chromatograms is presented in Fig. 2. Overall, the visualized TLC spots in $A$. oxyphylla under different storage conditions were the same as the sample stored at $4{ }^{\circ} \mathrm{C}$. Nootkatone was the most abundant volatile oil. TLC analysis confirmed that infection by A. flavus had no effect on the compositions of volatile oils of $A$. oxyphylla.

\section{GC-MS analysis}

Gas chromatography-mass spectrometry is a powerful technique used for the analysis of volatile components, since it provides qualitative and quantitative data for complex mixtures, such as those usually present in herbs (Carrasco et al. 2015). To further confirm the effects of storage conditions on the volatile compounds in $A$. oxyphylla, we used the GC-MS method to analyze the ethyl acetate extract. Chromatograms of all samples are shown in Additional file 1: Figure S3. The volatile compositions of A. oxyphylla are reported in Table 2. A total of 37 volatile components were identified by GC-MS. Of these, nootkatone (10.23-12.30\%), p-cymene (5.88-8.77\%), alloaromadendrene $(8.72-10.34 \%)$, aristolene epoxide (3.26-4.56\%), $\alpha$-selinene (1.87-2.43\%), $\alpha$-guaiene (1.85$2.31 \%), \alpha$-panasinsen $(1.78-2.20 \%)$, caryophyllene oxide (1.85-2.49\%), gingerol (2.04-2.94\%) were found to be the principal chemical constituents. Similar results have been reported in other studies (Feng et al. 2015; Miao 


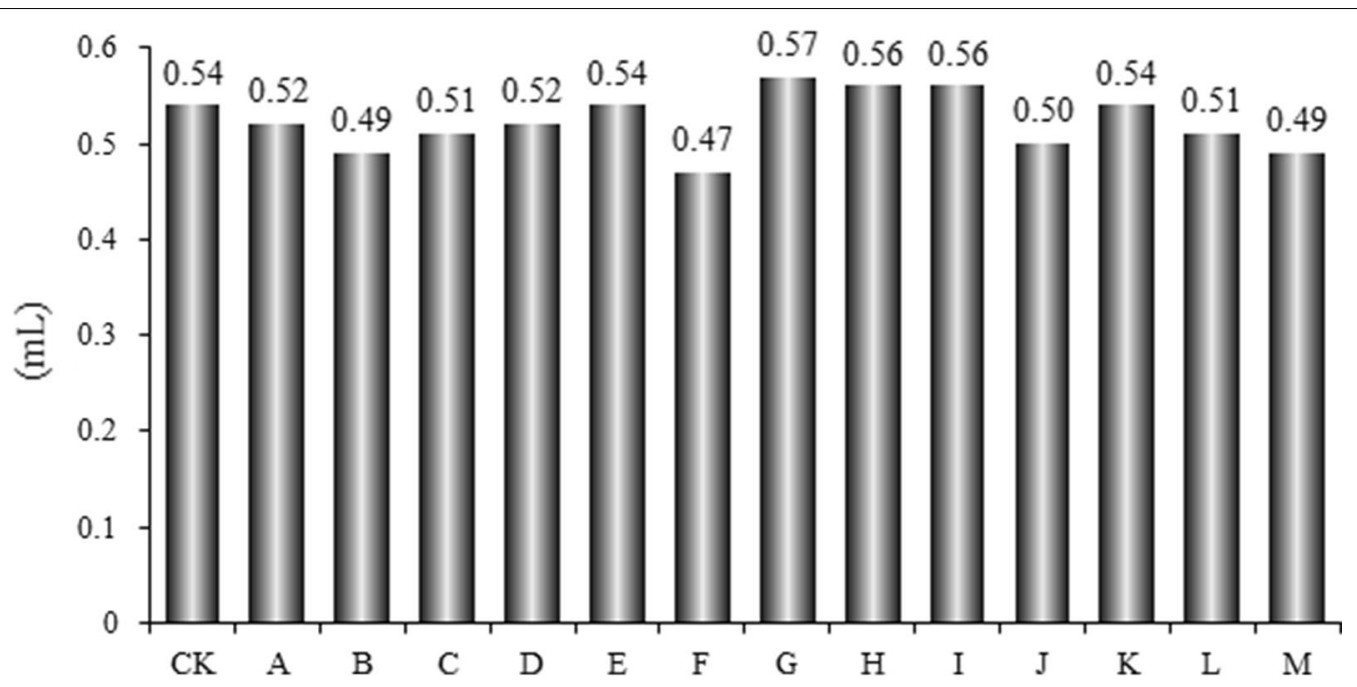

Fig. 1 Effects of storage conditions on the yields of volatile oil in A. oxyphylla

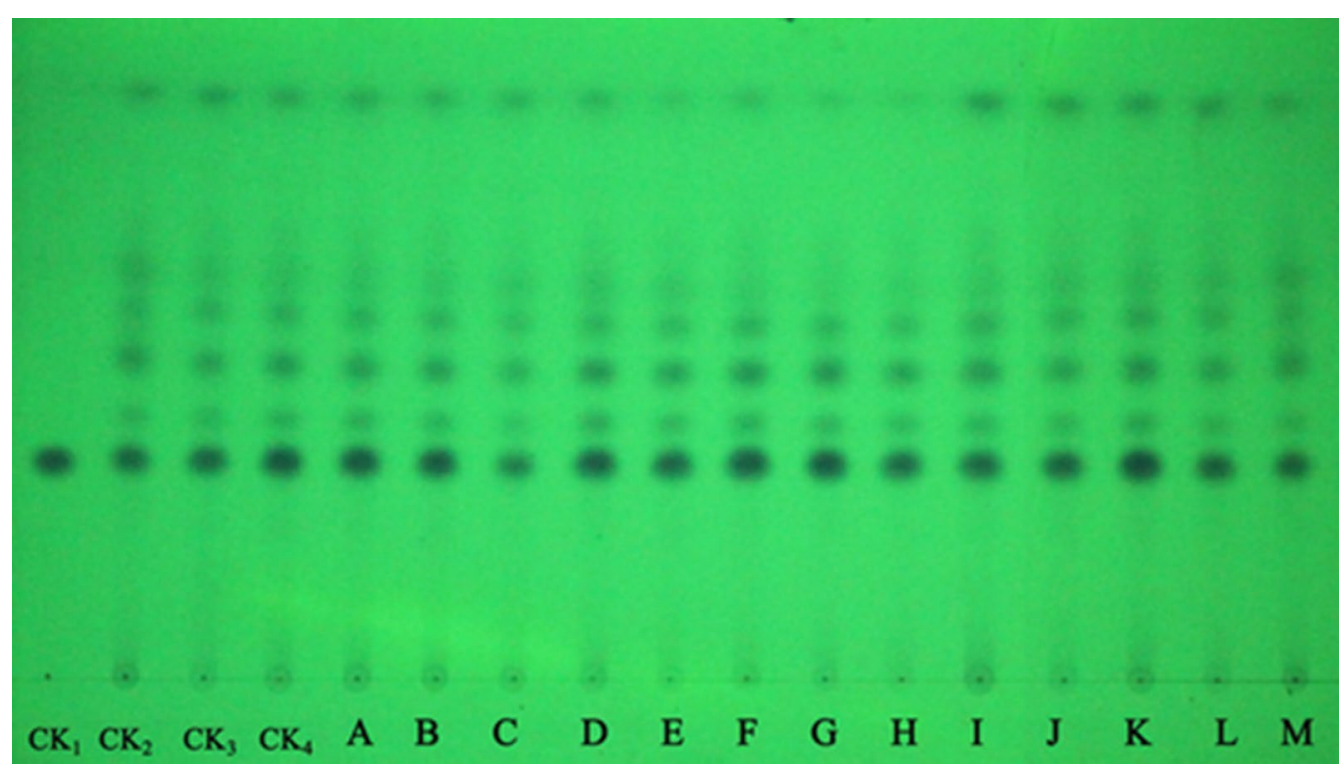

Fig. 2 TLC of A. oxyphylla under different storage conditions. (CK1: Nootkatone; CK2, CK3, CK4, Sample stored at $4{ }^{\circ} \mathrm{C}$ )

et al. 2015). As shown in Additional file 1: Figure S3 and Table 2, mold infection had small effects on the composition of volatile compounds in A. oxyphylla.

\section{Analysis of polysaccharides}

To quantify the polysaccharide content of A. oxyphylla, we used the phenol-sulfuric acid method, and used glucose as the standard monosaccharide. The calibration curve was linear within the range of 2.05-65.60 $\mu \mathrm{g} /$ $\mathrm{mL}$, with a correlation coefficient of 0.999 . We found that the polysaccharide content of A. oxyphylla was
12.91\% (Fig. 3). After co-incubation with A. flavus for 10 days, the polysaccharide content reduced remarkably, especially for the sample stored at $30.00{ }^{\circ} \mathrm{C}$ and $95.00 \%$ humidity. In addition, the polysaccharide content was significantly lower than control samples when A. oxyphylla was stored under the following conditions: $37.07{ }^{\circ} \mathrm{C}, 92.80 \%$ humidity (D); $40{ }^{\circ} \mathrm{C}, 87.5 \%$ humidity (F); and $30.00{ }^{\circ} \mathrm{C}, 87.5 \%$ humidity (I). Furthermore, under these conditions, A. flavus grew well and the aflatoxin concentrations were very high. It was worth noting that the polysaccharide content of several control 
Table 2 Relative area (\%) of common peaks in A. oxyphylla inoculated with A. flavus under different storage conditions

\begin{tabular}{|c|c|c|c|c|c|c|c|c|c|c|c|c|c|c|c|c|}
\hline No & RT & Compounds & A & B & C & D & $E$ & $F$ & G & $\mathbf{H}$ & I & J & $\mathbf{K}$ & L & M & CK \\
\hline 1 & 5.52 & a-Pinene & 0.38 & 0.38 & 0.29 & 0.39 & 0.37 & 0.41 & 0.33 & 0.27 & 0.36 & 0.27 & 0.38 & 0.36 & 0.34 & 0.41 \\
\hline 2 & 6.25 & $\beta$-Pinene & 0.44 & 0.50 & 0.41 & 0.49 & 0.33 & 0.34 & 0.29 & 0.52 & 0.35 & 0.41 & 0.46 & 0.36 & 0.40 & 0.40 \\
\hline 3 & 6.88 & p-Cymene & 8.77 & 7.12 & 6.19 & 8.31 & 8.14 & 6.77 & 5.94 & 6.98 & 6.52 & 6.34 & 6.54 & 5.88 & 6.61 & 7.71 \\
\hline 4 & 7.31 & Y-Terpinene & 1.03 & 1.00 & 0.88 & 1.04 & 0.84 & 0.74 & 0.82 & 0.74 & 0.63 & 0.75 & 0.72 & 0.86 & 0.84 & 0.65 \\
\hline 5 & 7.71 & Undecane & 1.20 & 1.31 & 1.23 & 1.08 & 1.54 & 1.50 & 1.04 & 1.25 & 1.39 & 1.67 & 1.44 & 1.68 & 78 & 1.05 \\
\hline 6 & 7.88 & Terpi & 0.43 & 0.54 & 0.39 & 0.48 & 0.54 & 0.63 & 0.53 & 0.40 & 0.40 & 0.51 & 0.45 & 0.47 & 0.64 & 0.53 \\
\hline 7 & 8.68 & Isopinc & 0.32 & 0.33 & 0.29 & 0.26 & 0.38 & 0.48 & 0.27 & 0.30 & 0.34 & 0.33 & 0.28 & 0.30 & 0.32 & 0.25 \\
\hline 8 & 9.52 & Dodecane & 0.89 & 0.90 & 0.92 & 0.84 & 0.81 & 0.91 & 0.75 & 0.90 & 1.06 & 1.21 & 1.00 & 1.18 & 1.02 & 0.91 \\
\hline 9 & 11.37 & Tridecane & 0.52 & 0.44 & 0.40 & 0.46 & 0.36 & 0.35 & 0.48 & 0.28 & 0.39 & 0.36 & 0.29 & 0.28 & 0.29 & 0.38 \\
\hline 10 & 14.5 & Copaene & 1.23 & 1.20 & 1.17 & 1.20 & 1.38 & 1.26 & 1.14 & 1.29 & 1.13 & 0.83 & 0.80 & 1.15 & 1.30 & 1.35 \\
\hline 12 & 17.19 & a-selinene & 2.13 & 1.97 & 2.22 & 2.44 & 1.87 & 1.89 & 2.04 & 2.37 & 2.24 & 2.00 & 1.90 & 2.43 & 1.96 & 2.05 \\
\hline 13 & 17.27 & $\beta$-yla & 0.74 & 0.69 & 0.78 & 0.75 & 0.69 & 0.76 & 0.72 & 0.75 & 0.79 & 0.69 & 0.64 & 0.70 & 0.75 & 0.69 \\
\hline 14 & 17.52 & Humulene & 0.54 & 0.60 & 0.47 & 0.49 & 0.60 & 0.48 & 0.52 & 0.64 & 0.64 & 0.54 & 0.56 & 0.56 & 0.58 & 0.50 \\
\hline 15 & 17.69 & Aromandendrene & 0.98 & 0.91 & 1.07 & 1.07 & 0.90 & 0.98 & 1.00 & 0.88 & 1.12 & 0.90 & 0.87 & 0.89 & 1.01 & 1.03 \\
\hline 16 & 18.71 & a-Guaiene & 2.11 & 1.88 & 1.98 & 2.20 & 2.19 & 1.78 & 2.02 & 2.31 & 2.31 & 1.98 & 1.98 & 2.15 & 1.85 & 1.98 \\
\hline 17 & 19.07 & Alloaromadendrene & 10.06 & 9.35 & 9.15 & 10.34 & 9.77 & 10.22 & 9.85 & 9.72 & 9.65 & 9.17 & 9.39 & 8.72 & 9.00 & 8.94 \\
\hline 18 & 19.53 & a-Farnesene & 0.27 & 0.47 & 0.36 & 0.38 & 0.38 & 0.31 & 0.42 & 0.27 & 0.31 & 0.32 & 0.32 & 0.26 & 0.30 & 0.29 \\
\hline 19 & 19.71 & $\beta$-Bisabolene & 0.32 & 0.32 & 0.36 & 0.31 & 0.36 & 0.30 & 0.32 & 0.27 & 0.28 & 0.33 & 0.38 & 0.27 & 0.26 & 0.32 \\
\hline 20 & 20.13 & cubedol & 0.62 & 0.59 & 0.78 & 0.56 & 0.68 & 0.55 & 0.61 & 0.57 & 0.57 & 0.61 & 0.70 & 0.70 & 0.66 & 0.59 \\
\hline 21 & 20.31 & (-)-a-Panasinsen & 2.20 & 1.89 & 2.01 & 1.78 & 2.60 & 1.80 & 2.20 & 1.92 & 2.10 & 2.02 & 1.96 & 1.95 & 2.05 & 2.27 \\
\hline 22 & 22.87 & trans-Z-a-Bisalolene epoxide & 0.47 & 0.54 & 0.58 & 0.51 & 0.48 & 0.47 & 0.46 & 0.50 & 0.56 & 0.43 & 0.47 & 0.43 & 0.46 & 0.42 \\
\hline 23 & 23.55 & Caryophyllene oxide & 2.11 & 2.21 & 2.39 & 1.85 & 2.24 & 2.29 & 1.93 & 1.93 & 2.13 & 2.37 & 2.49 & 2.22 & 2.20 & 1.95 \\
\hline 24 & 25.18 & Humulene 1,2-opoxide & 2.80 & 2.49 & 2.83 & 2.23 & 3.73 & 2.91 & 2.59 & 2.67 & 2.16 & 3.07 & 3.20 & .96 & 13 & 2.74 \\
\hline 25 & 26.23 & cis-Z-a-Bisalolene epoxide & 0.40 & 0.34 & 0.48 & 0.46 & 0.48 & 0.39 & 0.39 & 0.47 & 0.50 & 0.44 & 0.50 & 0.43 & 0.48 & 0.40 \\
\hline 26 & 28.17 & Caryophyllene oxide & 1.30 & 1.09 & 1.17 & 1.10 & 1.33 & 1.10 & 1.04 & 1.21 & 1.23 & 1.18 & 1.23 & 1.30 & 1.19 & 1.19 \\
\hline 27 & 28.47 & Y-Elemene & 0.94 & 0.92 & 0.89 & 1.03 & 0.95 & 0.80 & 0.83 & 0.86 & 0.88 & 0.89 & 0.94 & 0.94 & 0.93 & 0.83 \\
\hline 28 & 28.59 & ledol & 0.51 & 0.58 & 0.65 & 0.50 & 0.62 & 0.54 & 0.53 & 0.66 & 0.58 & 0.63 & 0.58 & 0.60 & 0.60 & 0.69 \\
\hline 29 & 29.1 & Isoaromadendrene epoxide & 1.49 & 1.45 & 1.39 & 1.19 & 1.44 & 1.45 & 1.27 & 1.47 & 1.68 & 1.29 & 1.51 & 1.60 & 1.64 & 1.37 \\
\hline 30 & 30.25 & Aristolene epoxide & 3.27 & 3.26 & 4.13 & 4.00 & 4.48 & 4.00 & 3.62 & 3.76 & 4.04 & 4.21 & 4.37 & 4.56 & 4.16 & 4.21 \\
\hline 31 & 31.04 & Calarene epoxide & 0.80 & 0.84 & 0.93 & 0.83 & 1.06 & 0.87 & 0.81 & 0.86 & 0.80 & 0.94 & 0.98 & 0.83 & 0.91 & 0.99 \\
\hline 32 & 31.47 & cis-Z-a-Bisabolene epoxide & 1.12 & 1.03 & 1.23 & 1.18 & 1.47 & 1.28 & 1.12 & 1.27 & 1.35 & 1.20 & 1.20 & 1.27 & 1.33 & 1.23 \\
\hline 33 & 33.32 & 4,5-di-epi-aristolochene & 0.90 & 0.99 & 1.05 & 0.85 & 1.12 & 0.85 & 0.84 & 0.86 & 0.87 & 0.98 & 1.03 & 1.12 & 1.09 & 1.00 \\
\hline 34 & 34.43 & Nootkatone & 10.31 & 10.55 & 10.99 & 10.35 & 10.23 & 11.13 & 12.30 & 10.34 & 11.31 & 10.49 & 10.48 & 11.66 & 10.59 & 10.66 \\
\hline 35 & 34.81 & Longipinocarvone & 0.95 & 1.03 & 0.96 & 1.05 & 1.04 & 0.90 & 0.92 & 1.08 & 0.85 & 0.99 & 1.02 & 1.09 & 1.01 & 1.04 \\
\hline 36 & 36.47 & Longifolenaldehyde & 0.93 & 1.01 & 1.18 & 1.23 & 0.90 & 1.15 & 0.95 & 1.70 & 1.80 & 1.07 & 1.05 & 1.11 & 1.02 & 1.20 \\
\hline 37 & 51.88 & Gingerol & 2.39 & 2.40 & 2.84 & 2.78 & 2.61 & 2.34 & 2.52 & 2.04 & 2.23 & 2.97 & 2.57 & 2.17 & 2.94 & 2.13 \\
\hline
\end{tabular}

samples (except A, E and G) under the same storage conditions was lower compared to samples stored in the refrigerator $\left(4{ }^{\circ} \mathrm{C}\right)$.

\section{Discussion}

Stored A. oxyphylla is a man-made ecosystem in which quality and nutritive changes occur because of interactions between physical, chemical and biological factors. Fungal spoilage and mycotoxin contamination are a major concern. If storage conditions are poorly managed, Aspergillus species can infect A. oxyphylla and mycotoxin contamination can occur (Chulze 2010). High temperatures and high humidity are two important factors leading to mold growth and aflatoxin contamination in the storage of cereals, feeds and herbs (Müller and Basedow 2007). A. oxyphylla is widely cultivated in tropical and subtropical regions, particularly in the Hainan province, which is located at $18^{\circ} 10^{\prime}-20^{\circ} 10^{\prime} \mathrm{N}$ latitude and $108^{\circ} 37^{\prime}-111^{\circ} 03^{\prime} \mathrm{E}$ longitude. There, the climate is warm, with plentiful rain and high humidity. Consequently, $A$. oxyphylla fruit may be more sensitive to mildew during storage such locations. In our previous study, none of the 


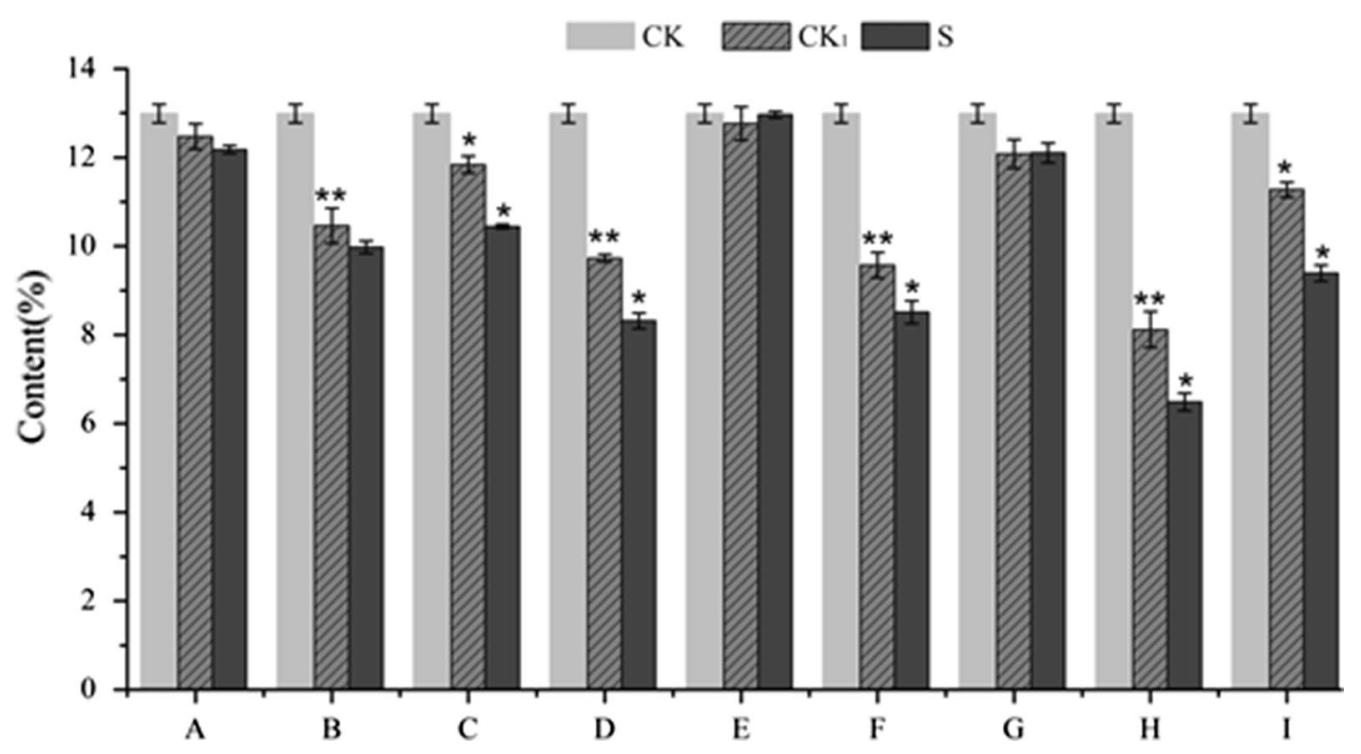

Fig. 3 Effects of storage condition on the content of polysaccharide of A. oxyphylla inoculated with A. flavus (* means significant at 0.05 level; ** means significant at 0.01 level; CK, Sample stored at $4{ }^{\circ} \mathrm{C} ; \mathrm{CK}_{1}$, Accompanying control; S, Sample under different storage conditions)

samples we tested had aflatoxin content exceeding the regulated maximum amount allowed (Zhao et al. 2017). However, high incidence and levels of AF contamination in A. oxyphylla has been reported (Zha et al. 2014; Zhang et al. 2008). Improved storage conditions to prevent $A$. oxyphylla spoilage and reduce aflatoxin contamination are recommended.

According to the results described above, $\mathrm{AFB}_{1}$ content should increase with increasing the temperature given the same humidity during storage, and vice verse. Our results showed that temperature and humidity played an important role in the growth of the A. flavus and the production of aflatoxins. After analysis using RSM, we concluded that the growth of A. flavus and production of aflatoxins could be minimized by maintaining the temperature below $25^{\circ} \mathrm{C}$ and the humidity below $85 \%$. Therefore, these conditions can be recommended as the best storage conditions for preventing the infection of the $A$. oxyphylla sample by A.flavus. Liu found that Areca catechu was not susceptible to mildew infection or toxin production in environments with humidity below $90 \%$ and temperature below $25^{\circ} \mathrm{C}$ (Liu et al. 2015). Furthermore, the best storage conditions for Radix Astragali to avoid A. flavus contamination were temperature and humidity below $20^{\circ} \mathrm{C}$ and $85 \%$ (Hu et al. 2015). These results may indicate that the optimal storage conditions of medicinal materials were related to TCMs.

Volatile oil is one of the main components of $A$. oxyphylla, and is used as a marker compound to assess the quality of $A$. oxyphylla in the Chinese pharmacopoeia (Chinese Pharmacopoeia Commission 2015).
The composition of volatile compounds in A. oxyphylla infected by A. flavus was similar to the control samples, which might be related to the properties of these components. A. flavus appears to mainly rely on polysaccharides, proteins, and fatty acids in A. oxyphylla as its source of nutrition, rather than the volatile components in volatile oils. These results have been confirmed by Prakash et al. (2015). The chemical variability of volatile oils due to variable ecological and geographical conditions, plant species, harvest time and extraction methodology were the major issues for their application as natural preservatives.

Polysaccharides are natural biological macromolecules that are composed of monosaccharide units bound together by glycosidic linkages (Liu et al. 2016). Polysaccharides are widely found in plants, which use them as energy storage molecules, structural components and protective substances (Le Floch et al. 2015). As a kind of carbohydrate, polysaccharides can provide a carbon source for the growth of fungi (Coutinho et al. 2009). As the main bioactive component of $A$. oxyphylla, polysaccharides can be used to systematically evaluate $A$. oxyphylla quality. Therefore, it is important to accurately analyze polysaccharides in $A$. oxyphylla under different storage conditions after infection with A. flavus. Aspergilli can use a wide variety of carbon compounds as a carbon source for its growth. These compounds include polysaccharides, oligo- and disaccharides, hexoses, pentoses, organic acids, aromatic compounds, alcohols, polyols, and fatty acids (Norihiro Tsukagoshi and Masashi 2001). Several species in the Aspergillus genus, including 
A. flavus, can produce and utilize enzymes that degrade polysaccharides (de Vries 2003). Therefore, polysaccharides could be used as the carbon source for the growth of $A$. flavus, which may be the main reason for the decrease in polysaccharides we observed in the $A$. oxyphylla samples after $A$. flavus infection. Furthermore, we found that the polysaccharide content of control samples (except A, E and G) under the tested storage conditions was lower compared to samples stored in the refrigerator $\left(4{ }^{\circ} \mathrm{C}\right)$. This was especially true for storage temperatures above $30{ }^{\circ} \mathrm{C}$. Under these conditions, enzymatic activity would promote polysaccharide degradation. Additionally, as carbohydrates are oxidized during respiration, the heat produced by respiration will accelerate polysaccharide loss. Certainly, the role of water in the degradation of polysaccharides cannot be ignored. These results confirm that storage conditions have an important influence on the quality of $A$. oxyphylla.

In brief, TCMs undergo numerous physical, chemical and microbiological changes, including mold infection, if they are stored under improper conditions. In this paper, how $A$. oxyphylla's storage conditions impact its quality and mildew growth was systematically studied. After mold infection, the volatile oil composition and the volatile components of $A$. oxyphylla were unaffected, but the polysaccharide content was reduced remarkably and mycotoxins were found, which would affect the quality and safety of $A$. oxyphylla. The crucial storage factors (including temperature and humidity) for preventing mold growth in A. oxyphylla were analyzed using RSM. Storing dry A. oxyphylla at temperatures below $25^{\circ} \mathrm{C}$ and humidity below $85 \%$ could effectively inhibit the development of $A$. flavus mold infection. Mildew infections caused by other toxic fungi and the resulting changes to bioactive constituents in A. oxyphylla will be explored in future experiments.

\section{Additional file}

Additional file 1: Figure S1. A. oxyphylla inoculated with A. flavus conidial suspension and cultured for 10 days. Figure S2. UPLC-MS/MS MRM chromatograms of 4 aflatoxins. Figure S3. GC-MS chromatograms of all the samples inoculated with $A$. flavus under different storage conditions. Table S1. Linearity, LODs, LOQs, of the 4 investigated mycotoxins.

\section{Abbreviations}

A. oxyphylla: Alpinia oxyphylla; A. flavus: Aspergillus flavus; TCMs: traditional Chinese medicines; AFs: aflatoxins; GC-MS: gas chromatography-mass spectrometry; UPLC-MS/MS: ultra-performance liquid chromatography coupled with tandem mass spectrometry; ESI: electrospray ionization; TLC: thin-layer chromatography; RSM: response surface methodology; CCD: central composite design.

\section{Authors' contributions}

XSZ,WJK and YKZ carried out the experimental studies and wrote the main manuscript text. JHW and MHY designed the study and performed the statistical analysis. All authors read and approved the final manuscript.

\begin{abstract}
Author details
${ }^{1}$ Hainan Branch Institute of Medicinal Plant Development, Chinese Academy of Medical Sciences \& Peking Union Medical College, Haikou 571100, China.

${ }^{2}$ Institute of Medicinal Plant Development, Chinese Academy of Medical Sciences \& Peking Union Medical College, Beijing 100193, China.
\end{abstract}

\section{Acknowledgements}

Not applicable.

\section{Competing interests}

The authors declare that they have no competing interests.

\section{Availability of data and materials}

All data in this manuscript were deposited in publicly available repositories in the Institute of Medicinal Plant Development, Chinese Academy of Medical Sciences \& Peking Union Medical College, Beijing, China.

\section{Funding}

This work was supported by the key Research Project (ZDYF2016174) of Hainan Province, and Hainan Science and Technology Project (ZDXM2015060).

\section{Publisher's Note}

Springer Nature remains neutral with regard to jurisdictional claims in published maps and institutional affiliations.

Received: 3 June 2017 Accepted: 5 July 2017

Published online: 11 July 2017

\section{References}

Amelin VG, Karaseva NM, Tret'yakov AV (2013) Chromatographic methods for the determination of mycotoxins in food products. J Anal Chem 68:195-205

Battilani P, Toscano P, Van der Fels-klerx HJ, Moretti A, Camardo Leggieri M, Brera C, Rortais A, Goumperis T, Robinson T (2016) Aflatoxin B contamination in maize in Europe increases due to climate change. Sci Rep 6:24328-24335

Carrasco A, Ortiz-Ruiz V, Martinez-Gutierrez R, Tomas V, Tudela J (2015) Lavandula stoechas essential oil from Spain: aromatic profile determined by gas chromatography-mass spectrometry, antioxidant and lipoxygenase inhibitory bioactivities. Ind Crop Prod 73:16-27

Chinese Pharmacopoeia Commission (2015) Pharmacopoeia of People's Republic of China. Chemical Industry Press, Beijing

Chulze SN (2010) Strategies to reduce mycotoxin levels in maize during storage: a review. Food Addit Contam A 27:651-657

Coutinho PM, Andersen MR, Kolenová K, de Vries RP (2009) Post-genomic insights into the plant polysaccharide degradation potential of Aspergillus nidulans and comparison to Aspergillus niger and Aspergillus oryzae. Fungal Genet Biol 46:161-169

de Vries RP (2003) Regulation of Aspergillus genes encoding plant cell wall polysaccharide-degrading enzymes; relevance for industrial production. Appl Microbiol Biot 61:10-20

Feng HH, Luo JY, Kong WJ, Dou XW, Wang YT, Zhao XS, Zhang WP, Li Q, Yang MH (2015) Enhancement effect of essential oils from the fruits and leaves of Alpinia oxyphylla on skin permeation and deposition of indomethacin. RSC Adv 5:38910-38917

Hu YC, Kong WJ, Liu QT, Zhao G, Yang MH (2015) Study on the influence of Aspergillus flavus on the quality of Radix astragali and its storage conditions optimization. Mod Chin Med 17:1133-1138

Le Floch A, Jourdes M, Teissedre PL (2015) Polysaccharides and lignin from oak wood used in cooperage: composition, interest, assays: A review. Carbohydr Res 41:94-102

Li YH, Chen F, Wang JF, Wang Y, Zhang JQ, Guo T (2013) Analysis of nine compounds from Alpinia oxyphylla fruit at different harvest time using UFLC-MS/MS and an extraction method optimized by orthogonal design. Chem Cent J 7:134-142

Liu HM, Kong WJ, Hu YC, Yang MH (2015) Application of response surface analysis in the investigation of storage condition of Areca catechu. World Chin Med 10:1129-1132 
Liu W, Liu YM, Zhu R, Yu RZ, Lu WS, Pan C, Yao WB, Gao XD (2016) Structure characterization, chemical and enzymatic degradation, and chain conformation of an acidic polysaccharide from Lycium barbarum L. Carbohydr Polym 147:114-124

Miao Q, Kong WJ, Zhao XS, Yang SH, Yang MH (2015) GC-FID coupled with chemometrics for quantitative and chemical fingerprinting analysis of Alpinia oxyphylla oil. J Pharm Biomed Anal 102:436-442

Müller P, Basedow T (2007) Aflatoxin contamination of pods of Indian Cassia senna L. (Caesalpinaceae) before harvest, during drying and in storage: reasons and possible methods of reduction. J Stored Prod Res 43:323-329

Norihiro Tsukagoshi TK, Masashi K (2001) Regulation of the amylolytic and (hemi-)cellulolytic genes in aspergilli. J Gen Appl Microbiol 47:1-19

Prakash B, Kedia A, Mishra PK, Dubey NK (2015) Plant essential oils as food preservatives to control moulds, mycotoxin contamination and oxidative deterioration of agri-food commodities-potentials and challenges. Food Control 47:381-391

Qin XM, Guo SX (2011) Mould and mycotoxin contamination of medicinal materials. Chin J Chin Mater Med 36:3397-3401

Sowa JM, Subbaiah PV (2004) Variable recoveries of fatty acids following the separation of lipids on commercial silica gel TLC plates selective loss of unsaturated fatty acids on certain brands of plates. J Chromatogr B 813:159-166

Wang H, Qi J, Han DQ, Xu T, Liu JH, Qin MJ, Zhu DN, Yu BY (2015) Cause and control of Radix ophiopogonis browning during storage. Chin J Nat Med 13:73-80

Zha YB, Yang CL, Wang XF, Zhang Z, Zhe YH, Lin L, Zeng SD (2014) Determination of Afatoxin contaminants in four south medicines by LC-MS/MS. J Anhui Agri Sci 36:12901-12903

Zhang AT, Shi YB, Zhang ZL, Li S, Lu HX, Sun PJ (2008) Determination AFB 1 content of part seed and fruit of traditional Chinese medicine by ELISA. J Med Res 37:48-49

Zhang J, Wider B, Shang H, Li X, Ernst E (2012) Quality of herbal medicines: challenges and solutions. Complement Ther Med 20:100-106

Zhao XS, Dong N, Feng JD, Yang MH (2013) Determination of polysaccharides content in Alpinia oxyphylla. Chin J Mod Appl Pharm 30:1070-1074

Zhao XS, Kong WJ, Wang S, Wei JH, Yang MH (2017) Simultaneous analysis of multiple mycotoxins in Alpinia oxyphylla by UPLC-MS/MS. World Mycotoxin J 10:41-51

\section{Submit your manuscript to a SpringerOpen ${ }^{\odot}$ journal and benefit from:}

- Convenient online submission

- Rigorous peer review

- Open access: articles freely available online

- High visibility within the field

- Retaining the copyright to your article

Submit your next manuscript at $\boldsymbol{\nabla}$ springeropen.com 